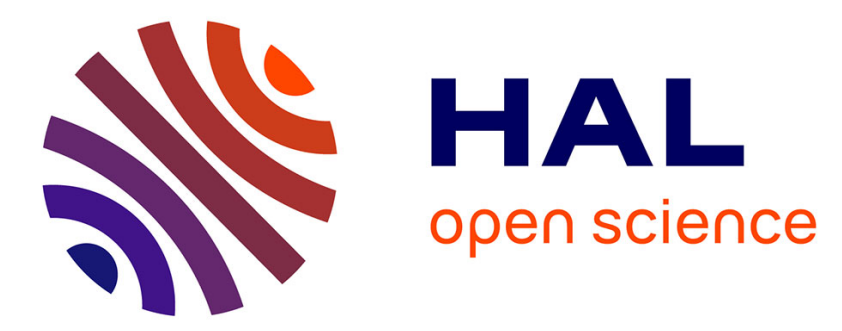

\title{
Extension of the Bending-Gradient theory to thick plates buckling: application to Cross Laminated Timber walls
}

Olivier Perret, Arthur Lebée, Cyril Douthe, Karam Sab

\section{To cite this version:}

Olivier Perret, Arthur Lebée, Cyril Douthe, Karam Sab. Extension of the Bending-Gradient theory to thick plates buckling: application to Cross Laminated Timber walls. Matériaux \& Techniques, 2016, 104 (4), 10.1051/mattech/2016021 . hal-01712210

\section{HAL Id: hal-01712210 \\ https://hal-enpc.archives-ouvertes.fr/hal-01712210}

Submitted on 26 Jun 2019

HAL is a multi-disciplinary open access archive for the deposit and dissemination of scientific research documents, whether they are published or not. The documents may come from teaching and research institutions in France or abroad, or from public or private research centers.
L'archive ouverte pluridisciplinaire HAL, est destinée au dépôt et à la diffusion de documents scientifiques de niveau recherche, publiés ou non, émanant des établissements d'enseignement et de recherche français ou étrangers, des laboratoires publics ou privés. 


\title{
Extension de la théorie du Bending-Gradient au voilement de plaques épaisses: application aux murs en bois lamellé-croisé
}

\author{
Extension of the Bending-Gradient theory to thick plates buckling: \\ Application to Cross Laminated Timber walls
}

\author{
Olivier Perret ${ }^{1}$, Arthur Lebée ${ }^{1}$, Cyril Douthe ${ }^{1}$, Karam Sab $^{1}$ \\ 1 : Université Paris-Est \\ Laboratoire Navier UMR 8205 CNRS, ENPC, IFSTTAR \\ 6-8 Avenue Blaise Pascal, Cité Descartes, Champs-sur-Marne F- 77455 Marne-la-Vallée \\ e-mail : olivier.perret@enpc.fr, arthur.lebee@enpc.fr, cyril.douthe@ifsttar.fr,karam.sab@enpc.fr
}

\begin{abstract}
Résumé
Dans cet article, la résolution du problème de flambement linéaire est présentée en utilisant la théorie du BendingGradient, qui est une extension de la théorie de plaque de Reissner au cas des plaques hétérogènes. Les résultats de référence sont issus d'une étude numérique 3D par éléments finis avec une application au cas des panneaux de bois lamellé-croisé, des stratifiés épais et fortement anisotropes. Les calculs de référence montrent que la charge critique de flambement et la contrainte de rupture du bois sont du même ordre de grandeur. La prise en compte du flambement dans le calcul de la résistance des murs en lamellé-croisé est donc une nécessité. Les résultats montrent, pour différentes géométries de plaques, que la théorie du Bending-Gradient estime précisément la charge critique des panneaux de bois lamellé-croisé contrairement aux théories classiques de Kirchhoff et de Reissner. De plus, il est démontré que la projection suggérée de la théorie du Bending-Gradient sur un modèle de Reissner donne des résultats très précis. Ce modèle pourrait ainsi faire l'objet d'une étude plus poussée sur le flambement de murs en lamellé-croisé avec prise en compte des imperfections initiales et de l'effet du comportement à long terme du bois.
\end{abstract}

\begin{abstract}
In this paper, the resolution of the linear buckling problem is presented using the Bending-Gradient theory which is an extension of the Reissner's plate theory to the case of heterogeneous plates. Reference results are taken from a 3D numerical analysis using finite-elements and applied to Cross Laminated Timber walls which are thick and highly anisotropic laminates. It is observed from reference results that critical buckling load and failure load are of the same order of magnitude. Buckling effects have then to be taken into account in the design of Cross Laminated Timber walls. It is then shown that for varying plate geometries, the Bending-Gradient theory predicts precisely the critical load of Cross Laminated Timber walls contrary to classical Kirchhoff and first order shear deformation theories. Moreover, it is demonstrated that the suggested projection of the Bending-Gradient on a Reissner's model gives very accurate results. This model could then be used in a more extensive study on the buckling of Cross Laminated Timber walls with initial geometrical imperfections and on the effects of the long term behavior of wood.
\end{abstract}

Mots Clés: Théorie du Bending-Gradient, Flambement linéaire de plaque, Bois lamellé-croisé, Cisaillement roulant, Contraste de raideur

Keywords: Bending-Gradient Theory, Linear Plate Buckling, Cross Laminated Timber, Rolling Shear, Stiffness contrast 


\section{Introduction}

Cross Laminated Timber is an innovative wooden structural product which consists in several lumber layers stacked crosswise and glued on their wide faces. Cross Laminated Timber constructions are assembled relatively quickly compared to buildings in steel or concrete and combines a low self weight and high membrane and bending stiffnesses. These attributes make it competitive in the prefabricated structures field with a low environmental impact. Cross Laminated Timber panels are classically used in walls, floors and roofs as load carrying plate elements.

During the last twenty years, Cross Laminated Timber buildings have gained in popularity and have grown higher and higher. As an example, the building Stadthaus, at Murray Grove in London, is the tallest modern timber building in the world. This nine-storey building is entirely designed in Cross Laminated Timber except for the first floor. The size-increasing of Cross Laminated Timber buildings leads to high compressive stresses in bearing walls which could lead to buckling. Indeed in timber, the radial-tangential shear stiffness, called also rolling shear stiffness, is two hundred times lower than the stiffness in fibers' direction. As rolling shear is solicited in cross layers during buckling, taking it into account seems mandatory with such contrast.

Since, one of the dimension of Cross Laminated Timber walls, the thickness, is significantly lower than the others, plate theories are appropriate to model Cross Laminated Timber walls. The classical theory of plates, also known as Kirchhoff-Love plate theory [1], is based on the assumption that the normal to the mid-plane of the plate remains normal after transformation neglecting thus the outof-plane shear strain. In his technical report [2], Leissa provided a large overview of the buckling of rectangular laminated composites by considering several loading configurations, boundary conditions and geometries of orthotropic and anisotropic laminates mainly based on the classical theory of plates. It is pointed that, when increasing the thickness, shear effects become more significant and the Kirchhoff model loses accuracy. To overcome this inaccuracy, Hencky [3] suggested a uniform shear strain distribution across thickness. This first order shear deformation theory (FOSDT), also called Reissner-Mindlin theory, is often associated with the shear correction factor $\kappa$, set to $\frac{5}{6}$ by Reissner [4] for homogeneous plates. Nevertheless, this theory does not insure zero shear stress at top and bottom surfaces and does not insure shear stress continuity at interfaces in laminated plates. Thus, Chow [5] then Whitney [6] suggested to introduce shear correction factors adapted to laminated plates by considering shear stress continuity across thickness with good results.

Several other theories have been introduced based on Hencky's work suggesting a higher order shear strain distribution across thickness such as Kaczkowski's model [7] where a cubic distribution of the in-plane displacement is suggested. Thus, numerous higher-order theories (HOSDT) have been suggested to model the shear strain distribution. The most refined HOSDT are zig-zag theories where a zig-zag distribution of the in-plane displacement is suggested. Most of these zig-zag theories are improvements of the Ambartsumian's model [8,9]. Although the zig-zag theories are very accurate for laminated composites, they are generally restricted to some specific configurations and laminaton schemes.

Lebée and Sab [10] suggests an improvement of the Reissner-Mindlin theory by considering the gradient of the bending moment to describe the shear behavior of the plate. The so-called BendingGradient (BG) theory presents excellent results for the cylindrical bending of laminates [11]. The Bending-Gradient theory has recently been extended to plate buckling by Perret et al [12]. The main aspects of the Bending-Gradient theory and its extension to plate buckling are recalled in this paper and the main results are presented.

First, the Bending-Gradient theory in first recalled in section 2 and extended to the problem of stability. A projection on a simplified Reissner model is also discussed. Then, in section 3, a 3D numerical study is conducted and provides reference results. Finally, analytical results from the Bending-Gradient theory and more classical models are compared with reference results in section 4. 


\section{Linear buckling of plates with the Bending-Gradient theory}

\subsection{Notations}

Vectors and higher-order tensors, up to sixth order, are used in the following. When using short notation, several underlining styles are used: vectors are straight underlined, $\underline{\boldsymbol{u}}$. Second order tensors are underlined with a tilde: $\underset{\sim}{\boldsymbol{M}}$ and $\boldsymbol{\sigma}$. Third order tensors are underlined with a parenthesis: $\boldsymbol{R}$ and $\underset{\sim}{\Gamma}$. Fourth order tensors are doubly underlined with a tilde: $\underset{\sim}{\boldsymbol{D}}$ and $\underset{\widetilde{C}}{\boldsymbol{\sigma}}$. Sixth order tensors are doubly underlined with a parenthesis: $\boldsymbol{h}$. The full notation with indices is also used. Then we follow Einstein's notation on repeated indices. Furthermore, Greek indices $\alpha, \beta, \delta, \gamma \in\{1,2\}$ denotes in-plane dimensions and Latin indices $i, j, k, l \in\{1,2,3\}$, all three dimensions.

Three contraction products are defined, the usual dot product $\left(\underline{\boldsymbol{a}} \cdot \underline{\boldsymbol{b}}=a_{i} b_{i}\right)$, the double contraction product $\left(\underset{\sim}{\boldsymbol{a}}: \underset{\sim}{\boldsymbol{b}}=a_{i j} b_{j i}\right)$ and a triple contraction product $\left(\underline{\boldsymbol{a}}: \underline{\boldsymbol{b}}=a_{\alpha \beta \gamma} b_{\gamma \beta \alpha}\right)$. It should be noticed that closest indices are summed together in contraction products. The derivation operator $\underline{\nabla}$ is also formally represented as a vector: $\underset{\sim}{\boldsymbol{a}} \cdot \underline{\boldsymbol{\nabla}}=a_{i j} \nabla_{j}=a_{i j, j}$ is the divergence and $\underset{\sim}{\boldsymbol{a}} \otimes \underline{\boldsymbol{\nabla}}=a_{i j} \nabla_{k}=a_{i j, k}$ is the gradient. Here $\otimes$ is the dyadic product.

\subsection{The Bending-Gradient theory}

Full details about the Bending-Gradient theory are provided in $[10,11]$. In the general case, membrane and bending parts of the problem are studied together but it is shown in the following section that the buckling problem can be solved considering only the bending part of the problem.

\subsubsection{Generalized stress and strain fields}

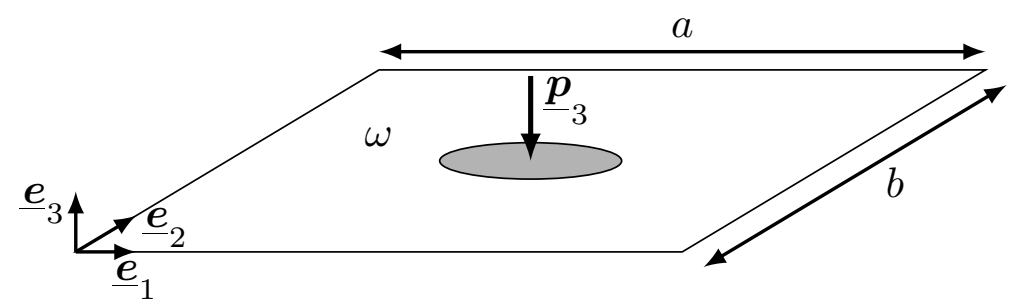

Figure 1: 2D rectangular plate under out-of-plane external load Plaque rectangulaire 2D sous chargement hors-plan

We consider a linear elastic rectangular plate of length $a$, width $b$ and thickness $h$, which mid-plane is the $2 \mathrm{D}$ domain $\omega=([0, a],[0, b])$. The $3 \mathrm{D}$ domain is then defined as $\Omega=\omega \times[-h / 2, h / 2]$. Cartesian coordinates $x_{1}, x_{2}, x_{3}$ are used in the reference frame $\left(\underline{\boldsymbol{e}}_{1}, \underline{\boldsymbol{e}}_{2}, \underline{\boldsymbol{e}}_{3}\right)$. For a plate which constitutive material follows monoclinic symmetry according to $\omega$, the membrane part and the bending part of the problem are uncoupled. Thus, the conventional generalized stresses for plates are defined from the 3D stress field $\sigma_{i j}$ as follows:

$$
\begin{cases}M_{\alpha \beta}=\int_{-\frac{h}{2}}^{\frac{h}{2}} x_{3} \sigma_{\alpha \beta} d x_{3} & \text { on } \omega \\ Q_{\alpha}=\int_{-\frac{h}{2}}^{\frac{h}{2}} \sigma_{\alpha 3} d x_{3} & \text { on } \omega\end{cases}
$$

where $M_{\alpha \beta}$ is the bending moment and $Q_{\alpha}$ the shear force. $\boldsymbol{M}$ follows the classical symmetry of stress tensors: $M_{\alpha \beta}=M_{\beta \alpha}$. Moreover, an additional static unknown is introduced: the generalized shear force $R_{\alpha \beta \gamma}=M_{\alpha \beta, \gamma}$. The 2D third-order tensor $\boldsymbol{R}$ complies with the following symmetry: $R_{\alpha \beta \gamma}=R_{\beta \alpha \gamma}$. It is possible to derive the shear force $\underline{\boldsymbol{Q}}$ from $\underset{\boldsymbol{R}}{\boldsymbol{R}}$ with: $Q_{\alpha}=R_{\alpha \beta \beta}$ or $\underline{\boldsymbol{Q}}=\underset{\sim}{\boldsymbol{i}}: \underline{\boldsymbol{R}}$. $\underset{\sim}{\boldsymbol{i}}$ is 
the identity for in-plane tensor: $i_{\alpha \beta \gamma \delta}=\frac{1}{2}\left(\delta_{\alpha \gamma} \delta_{\beta \delta}+\delta_{\alpha \delta} \delta_{\beta \gamma}\right)$ where $\delta_{\alpha \beta}$ is the Kronecker symbol $\delta_{\alpha \beta}=1$ if $\alpha=\beta$ and 0 if $\alpha \neq \beta$.

In the case of highly anisotropic laminated plates the distinction between every compononents of the gradient of the bending moment is necessary for deriving good estimate of the deflection and local transverse shear distribution through the thickness [11].

The full bending gradient $\boldsymbol{R}$ has six components whereas $\underline{\boldsymbol{Q}}$ has two components. Thus, using the full bending gradient as static unknown introduces four additional static unknowns. More precisely: $R_{111}$ and $R_{222}$ are respectively the cylindrical bending part of shear forces $Q_{1}$ and $Q_{2}, R_{121}$ and $R_{122}$ are respectively the torsion part of these shear forces and $R_{112}$ and $R_{221}$ are linked to strictly selfequilibrated stresses.

Thus, from generalized stress definition (Eq. 1), the 3D equilibrium equations $\sigma_{i j, j}=0$ are rewritten:

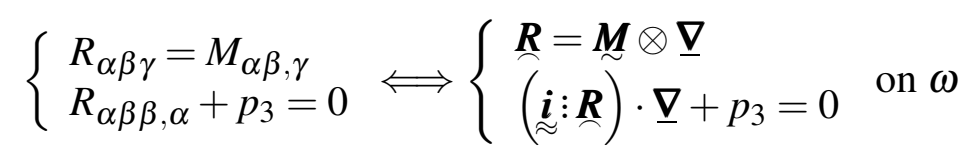

where $p_{3}$ is the out-of-plane load (cf Fig. 1).

Generalized stresses $\underset{\sim}{\boldsymbol{M}}$ and $\boldsymbol{R}$ work respectively with the associated strain variables: the curvature $\underset{\chi}{\chi}$ and the generalized shear strain $\Gamma$. These strain fields must comply with compatibility equations:

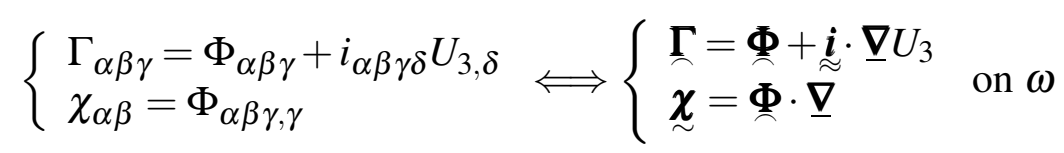

where $\Phi$ is the third-order tensor related to generalized rotations and $U_{3}$ is the average out-of-plane displacement. $\Phi$ and $\Gamma$ are $2 \mathrm{D}$ third-order tensors following the symmetry $\Gamma_{\alpha \beta \gamma}=\Gamma_{\beta \alpha \gamma}$.

\subsubsection{Bending-Gradient constitutive equations}

Assuming full uncoupling between $\underset{\boldsymbol{R}}{\text { and }} \underset{\sim}{\boldsymbol{M}}$, the Bending-Gradient plate constitutive equations are:

$$
\left\{\begin{array} { l } 
{ M _ { \alpha \beta } = D _ { \alpha \beta \gamma \delta } \chi _ { \delta \gamma } } \\
{ \Gamma _ { \alpha \beta \gamma } = h _ { \alpha \beta \gamma \delta \varepsilon \zeta } R _ { \zeta \varepsilon \delta } }
\end{array} \Longleftrightarrow \left\{\begin{array}{l}
\underset{\sim}{\boldsymbol{M}}=\underset{\sim}{\boldsymbol{D}}: \underset{\sim}{\boldsymbol{\chi}} \\
\underset{\sim}{\boldsymbol{\Gamma}}: \underset{\sim}{\boldsymbol{R}}
\end{array} \text { on } \omega\right.\right.
$$

where $\underset{\sim}{\boldsymbol{D}}=\underset{\approx}{\boldsymbol{d}}{ }^{-1}$ is the conventional Kirchhoff-Love fourth-order bending tensor classically defined as follows:

$$
D_{\alpha \beta \gamma \delta}=\int_{-\frac{h}{2}}^{\frac{h}{2}} x_{3}^{2} C_{\alpha \beta \gamma \delta}^{\sigma}\left(x_{3}\right) d x_{3} \quad \text { where } C_{\alpha \beta \gamma \delta}^{\sigma}=C_{\alpha \beta \gamma \delta}-\frac{C_{\alpha \beta 33} C_{\gamma \delta 33}}{C_{3333}}
$$

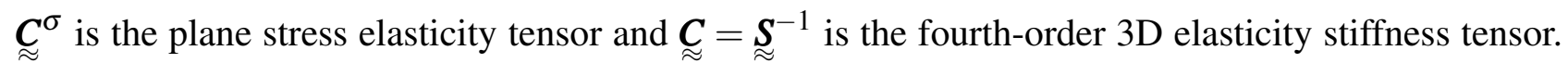
$\stackrel{\boldsymbol{h}}{\mathrm{h}}$ is the sixth-order generalized shear compliance tensor defined in [10] as follows:

$$
\underset{\boldsymbol{h}}{\boldsymbol{h}}=\int_{-\frac{h}{2}}^{\frac{h}{2}}\left(\int_{\frac{-h}{2}}^{x_{3}} z \underset{\approx}{\boldsymbol{d}}: \underset{\approx}{\boldsymbol{C}} d z\right) \cdot \underset{\sim}{\boldsymbol{g}} \cdot\left(\int_{\frac{-h}{2}}^{x_{3}} z \underset{\approx}{\boldsymbol{C}}{ }^{\sigma}: \underset{\approx}{\boldsymbol{d}} d z\right) d x_{3}
$$

where $g_{\alpha \beta}=4 S_{\alpha 3 \beta 3}$ is the out-of-plane Reissner shear compliance tensor. The fourth-order tensor $\underset{\sim}{\boldsymbol{D}}$ and the sixth order tensor $\underset{\sim}{\boldsymbol{h}}$ follow the major symmetry: $D_{\alpha \beta \gamma \delta}=D_{\delta \gamma \beta \alpha}, h_{\alpha \beta \gamma \delta \varepsilon \zeta}=h_{\zeta \varepsilon \delta \gamma \beta \alpha}$ and the minor symmetry: $D_{\alpha \beta \gamma \delta}=D_{\beta \alpha \gamma \delta}, h_{\alpha \beta \gamma \delta \varepsilon \zeta}=h_{\beta \alpha \gamma \delta \varepsilon \zeta}$.

\subsubsection{The shear compliance projection of the Bending-Gradient model on a Reissner model}

In the case of homogeneous plates, it has been demonstrated that the Bending-Gradient model strictly reduces to a Reissner model [10]. Indeed, it can be shown that $h_{\alpha \beta \gamma \delta \varepsilon \zeta}=i_{\alpha \beta \gamma \eta} f_{\eta \theta_{\theta}}^{R} i_{\theta \delta \varepsilon \zeta}$ where the second-order shear compliance tensor is classically defined as $f_{\alpha \beta}^{R}=\frac{6}{5} h S_{\alpha 3 \beta 3}$ in the FOSDT. For 
this reason, the Bending-Gradient theory can be seen as an extension to heterogeneous plates of the Reissner theory.

Thus, from assumptions on Bending-Gradient generalized shear variables as a function of Reissner shear variables, several projections (or reduction) of the Bending-Gradient theory can be done on Reissner models. Following this idea, Lebée and Sab [10] considered a new set of static variables from the generalized shear tensor $\boldsymbol{R}$ :

$$
\begin{gathered}
Q_{\alpha}=R_{\alpha \beta \beta}, \quad R_{221}, \quad R_{112}, \\
\Delta Q_{1}=R_{111}-2 R_{122}, \quad \Delta Q_{2}=R_{222}-2 R_{121}
\end{gathered}
$$

where $\Delta Q_{1}, \Delta Q_{2}, R_{221}$ and $R_{112}$ are four self-equilibrated static unknowns. They are clearly set apart from shear forces $Q_{\alpha}$. Thus, it is assumed that these unknowns do not contribute to the transverse shear energy and only the contribution of Reissner shear forces $Q_{1}$ and $Q_{2}$ is kept. This is equivalent to set $\boldsymbol{R}=\frac{2}{3} \boldsymbol{i} \cdot \boldsymbol{Q}$. The second-order shear compliance tensor of this projection is then expressed

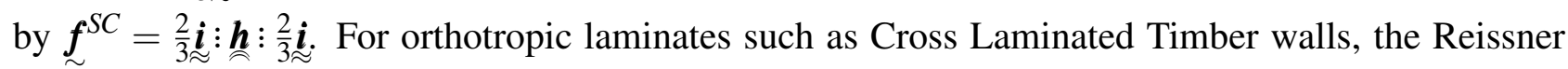
second order shear compliance tensor of the shear compliance projection takes the following form $[13,14,15]$ :

$$
{\underset{\sim}{f}}^{S C}=\frac{4}{9}\left(\begin{array}{cc}
h_{111111}+h_{122221}+2 h_{111221} & 0 \\
0 & h_{222222}+h_{121121}+2 h_{121222}
\end{array}\right)
$$

This projection is used by Lebée and Sab $[10,11]$ to estimate the Reissner-Mindlin part of the sixth-order tensor $\boldsymbol{h}$ by:

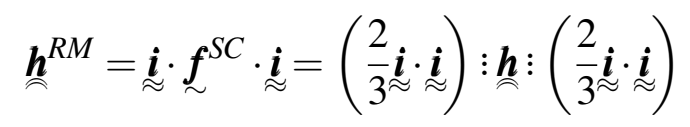

The following relative distance $\Delta^{R M / B G}$ between Bending-Gradient and Reissner-Mindlin models on bending problem is suggested in [10]:

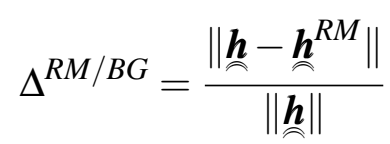

where the norm of sixth order tensor is defined by:

$$
\|\boldsymbol{h}\|=\sqrt{{ }^{t} \stackrel{h}{\curvearrowright}:: \stackrel{h}{h}}=\sqrt{h_{\alpha \beta \gamma \delta \varepsilon \zeta} h_{\alpha \beta \gamma \delta \varepsilon \zeta}}
$$

\subsubsection{Simple support boundary conditions}

On the plate boundaries $\partial \omega$, the normal and the tangent vectors are noted $\underline{\boldsymbol{n}}$ and $\underline{\boldsymbol{t}}$ respectively. In the Reissner plate model, a simple support is modeled by restraining the out-of-plane displacement $U_{3}$ and the tangent rotation $\varphi_{t}$ :

$$
\left\{\begin{array}{l}
U_{3}=0 \\
M_{n n}=0 \text { on } \partial \omega \\
\varphi_{t}=0
\end{array}\right.
$$

Although the first two conditions of Equation (6) can be easily transposed from the Reissner model to the Bending-Gradient model, it is not the case of the third one since generalized rotations $\Phi_{\alpha \beta \gamma}$ are a combination of both rotations $\varphi_{\alpha}$. Nevertheless, it can be demonstrated that if the constitutive material is orthotropic with respect to $(\underline{\boldsymbol{n}}, \underline{\boldsymbol{t}})$ as Cross Laminated Timber walls, $\Phi_{n t n}$ is working with $M_{n t}$ and is then the only component of $\boldsymbol{\Phi}$ directly related to the tangent displacement $u_{t}$ and then to the tangent rotation $\varphi_{t}[13]$.

Moreover, in the Bending-Gradient model, general boundary conditions differ from Reissner's ones because of the additional variables. Indeed, contrary to the Reissner's model, the bending moment $M_{t t}$ is set to zero. Since $M_{t t}=\int_{-\frac{h}{2}}^{\frac{h}{2}} x_{3} \sigma_{t t} d x_{3}$ (cf Eq. 1a), it seems to involve a 3D stress component 
to which no 3D boundary condition should be applied. Actually it does since for an heterogeneous plate $\sigma_{\alpha \beta}$ is a linear combination of all bending moment components $M_{\alpha \beta}[10,13]$. The condition $M_{t t}=0$ is thus related to the boundary layer ensuring $\sigma_{n n}=0$.

The simple support boundary is then defined in the Bending-Gradient theory by:

$$
\left\{\begin{array}{l}
U_{3}=0 \\
M_{n n}=M_{t t}=0 \quad \text { on } \partial \omega \\
\Phi_{n t n}=0
\end{array}\right.
$$

\subsection{Linear buckling analysis}

We assume that the plate is uniformly pre-loaded with the compression membrane stress ${\underset{\sim}{\sim}}^{0}(\lambda)=$ $-\lambda \underline{\boldsymbol{e}}_{1} \otimes \underline{\boldsymbol{e}}_{1}$ where $\lambda$ is a positive scalar. The corresponding stress field $\boldsymbol{\sigma}^{0}$ complies with the equality $N_{\alpha \beta}^{0}=\int_{-\frac{h}{2}}^{\frac{h}{2}} \sigma_{\alpha \beta}^{0} d x_{3}$. We consider now the perturbed state $\underline{\boldsymbol{u}}=\underline{\boldsymbol{u}}_{0}+\underline{\boldsymbol{\xi}}$ where $\underline{\boldsymbol{u}}_{0}$ is the initial displacement field and $\underline{\xi}$ a small perturbation which complies with kinematic boundary conditions. The Piola-Lagrange stress tensor $\boldsymbol{\sigma}$ is expressed at first order as:

$$
\sigma_{i j}=\sigma_{i j}^{0}+\xi_{i, k} \sigma_{k j}^{0}+C_{i j k l} \frac{1}{2}\left(\xi_{k, l}+\xi_{l, k}\right)
$$

Assuming that the third term in Equation (8) takes the same form as the Bending-Gradient stress tensor $\underline{\boldsymbol{\sigma}}^{\mathrm{BG}}$, depending on $\underset{\sim}{\boldsymbol{M}}$ and $\boldsymbol{R}[10]$, and noting that $\underline{\boldsymbol{\xi}} \approx U_{3}\left(x_{1}, x_{2}\right) \cdot \underline{\boldsymbol{e}}_{3}$ at the leading order, it is deduced from the equilibrium $\sigma_{i j, j}$ and after integration through the thickness, that the second equation of equilibrium (2) may be written [12]:

$$
R_{\alpha \beta \beta, \alpha}-\lambda U_{3,11}=0 \quad \text { on } \omega
$$

The simplification of the set of equilibrium (Eq. 2, 9), compability (Eq. 3) and constitutive equations (Eq. 4) results in the following eigenvalue problem:

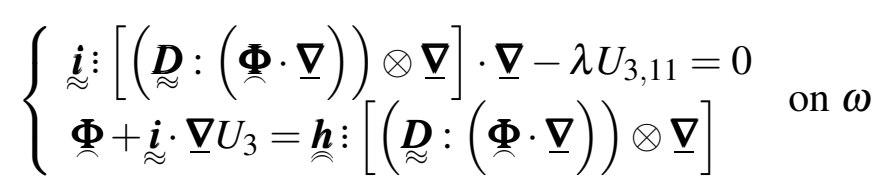

This problem is solved, looking for expressions of $U_{3}$ and $\boldsymbol{\Phi}$ in the form of Fourier-like series. Considering kinematic compatibility (Eq. 3), simple support boundary conditions and the geometry of the plate, which is rectangular with each layer's principal axes coinciding with rectangular reference frame $\left(\underline{\boldsymbol{e}}_{1}, \underline{\boldsymbol{e}}_{2}, \underline{\boldsymbol{e}}_{3}\right)$, expressions of $U_{3}$ and $\boldsymbol{\Phi}$ are looked in the following form:

$$
\begin{aligned}
& U_{3}=\sum_{m=1}^{\infty} \sum_{n=1}^{\infty} U_{3}^{m n} \sin \left(K_{m} x_{1}\right) \sin \left(K_{n} x_{2}\right) \\
& \Phi_{\alpha \beta \gamma}=\sum_{m=1}^{\infty} \sum_{n=1}^{\infty} \Phi_{\alpha \beta \gamma}^{m n} \cos \left(K_{m} x_{1}\right) \sin \left(K_{n} x_{2}\right) \quad \text { for } \Phi_{111}, \Phi_{221} \text { and } \Phi_{122} \\
& \Phi_{\alpha \beta \gamma}=\sum_{m=1}^{\infty} \sum_{n=1}^{\infty} \Phi_{\alpha \beta \gamma}^{m n} \sin \left(K_{m} x_{1}\right) \cos \left(K_{n} x_{2}\right) \quad \text { for } \Phi_{121}, \Phi_{112} \text { and } \Phi_{222} \\
& \text { where } K_{m}=\frac{m \pi}{a} \text { and } K_{n}=\frac{n \pi}{b} \text { for }\{m, n\} \in \mathbb{N}^{* 2}
\end{aligned}
$$

$U_{3}^{m n}$ and $\Phi_{\alpha \beta \gamma}^{m n}$ are respectively the amplitudes of each term of the out-of-plane displacement and the generalized rotations associated with the $\{m, n\}$ mode.

These expressions are injected in the buckling problem (Eq. 10). It is noticed from the orthogonality of the series, that each equation is satisfied only if it is satisfied for each individual term in cosine and sine series. Thus all harmonic functions can be omitted in the following developments. 
Solutions of the buckling problem are then eigenmodes $\left(U_{3}^{m n}, \Phi_{\alpha \beta \gamma}^{m n}\right)$ associated with the corresponding eigenvalue $\lambda_{m n}$. The detailed formulation of the exact solution can be found in [12].

Here, we are only interested in the lowest value $\lambda_{m n}$ among all $\{m, n\} \in \mathbb{N}^{2}$. The lowest mode $\{m, n\}$ depends on the plate aspect ratio $\frac{a}{b}$, the plate slenderness $\frac{b}{h}$ and the material characteristics. In the studied domain, namely $\frac{a}{b} \in[0.5,2]$ and $\frac{b}{h} \in[10,35]$, with material characteristics given in Tab. 1 , it is observed that the lowest eigenvalue is always $\lambda_{11}$ or $\lambda_{21}$ (cf Section 4.2).

\section{3D reference model for Cross Laminated Timber}

A 3D numerical study is performed using the finite element software ABAQUS. These numerical results will be considered as the reference results for the comparison with analytical results in section 4.

\subsection{The 3D linear buckling problem}

The linear buckling analysis is performed in two steps: the plate is initially pre-stressed with the uniform membrane stress $\underset{\sim}{\boldsymbol{N}}(\lambda)=-\lambda \underline{\boldsymbol{e}}_{1} \otimes \underline{\boldsymbol{e}}_{1}$ and then buckling modes satisfying boundary conditions are calculated as linear perturbations of the reference state.

\subsubsection{The pre-stressed state}

The pre-stressed state $\underset{\sim}{\boldsymbol{\sigma}}$ equivalent to the membrane stress $\underset{\sim}{\boldsymbol{N}}$ defined in 2.3 satisfies the relationship $N_{\alpha \beta}=\int_{-\frac{h}{2}}^{\frac{h}{2}} \sigma_{\alpha \beta}\left(x_{3}\right) d x_{3}$. Contrary to homogeneous plates, $\underset{\sim}{\boldsymbol{\sigma}}$ is not uniform in laminated plates but depends on the $x_{3}$ coordinates and cannot be easily modeled by external loads. Nevertheless, from the membrane constitutive law, it is possible to calculate the uniform in-plane strain distribution in the pre-stressed plate:

$$
\begin{aligned}
& \frac{1}{2}\left(U_{\alpha, \beta}+U_{\beta, \alpha}\right)=a_{\alpha \beta \gamma \delta} N_{\delta \gamma} \Leftrightarrow\left(\underline{\boldsymbol{U}} \otimes^{s} \underline{\boldsymbol{\nabla}}\right)=\underset{\sim}{\boldsymbol{a}}: \underset{\sim}{\boldsymbol{N}}
\end{aligned}
$$

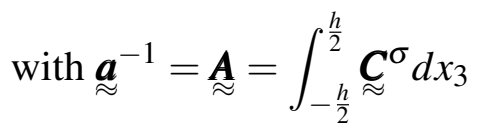

where $\underline{U}$ is the average in-plane displacement and $\underset{\sim}{\boldsymbol{A}}$ the membrane stress tensor. Thus, in the case of a unidirectional load, the pre-stressed state may be modeled by applying uniform displacement conditions on boundaries (cf Fig. 2).

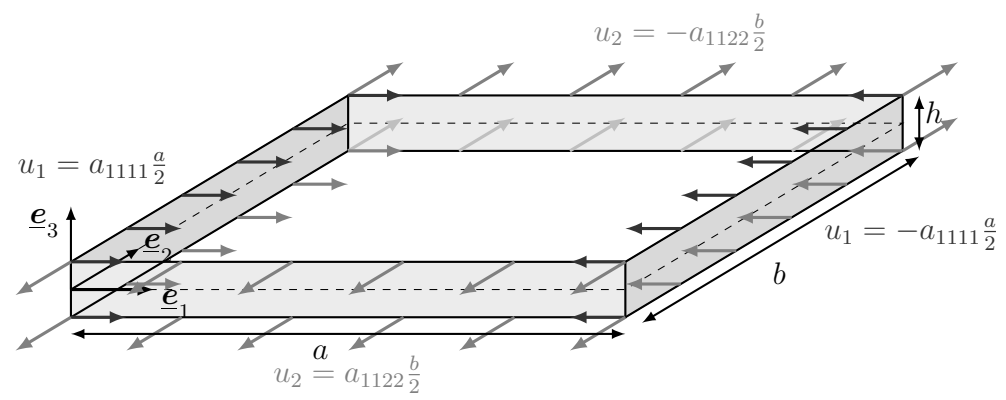

Figure 2: Model of the 3D uniform membrane pre-stress Modèle du pré-chargement 3D de membrance 


\subsubsection{Simple support boundary conditions}

During the second step, the buckling modes are calculated as additional perturbed states which comply with boundary conditions. Thus, 3D simple support boundary conditions must be modeled in this step. Simple support boundary conditions (cf Section 2.2.4) applied on the 2D plate models can not be transposed directly to $3 \mathrm{D}$ problems. Indeed in $3 \mathrm{D}$, there are no rotation fields $\underline{\varphi}$ but only three translationnal degrees of freedom. Nevertheless we may assume that restraining the tangent displacement $u_{t}$ is a good 3D model to set tangent rotation $\varphi_{t}$ to zero. These equivalent 3D simple support boundary conditions are shown in Figure 3 for a rectangular plate.

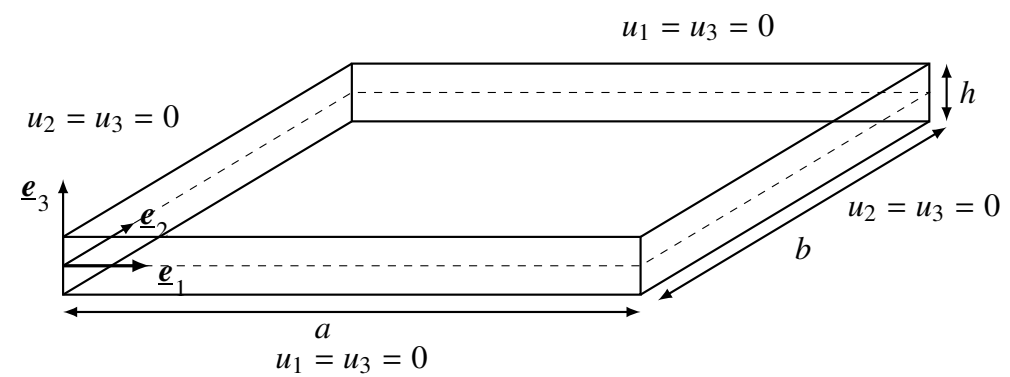

Figure 3: 3D Boundary conditions of the buckling mode calculation step Conditions aux limites 3D lors de l'étape de calcul des modes de flambement

\subsubsection{Definition of the numerical model}

The C3D20R element, a quadratic 3D brick-element with 20 nodes is used to mesh the plate. There are three degrees of freedom at each node, one for each translation. A reduced integration with only 8 integration points is chosen to evaluate the material response in each element. A convergence study was performed to find the most suitable mesh with an accuracy of $0.1 \%$ in terms of buckling load. In order to reduce the time of calculation, elements are voluntary stretched in the plane directions (cf Fig. 4).

\subsubsection{Timber elastic characteristics and Cross Laminated Timber configurations}

Timber is a material with a high anisotropy which is often modeled as a linear orthotropic material. Norway Spruce mechanical caracteristics are used in the present paper because it is one of the most used species in timber construction. References values will be taken from Keunecke et al [16]. For an orthotropic material, $E_{i}, G_{i j}$ and $v_{i j}$ stand for Young and shear modulii and Poisson's ratios respectively. $L, R$ and $T$ stand for longitudinal, radial and tangential directions. The conventional relationship $\frac{E_{i}}{E_{j}}=\frac{v_{i j}}{v_{j i}}$ is used here.

\begin{tabular}{|r|r|r|r|r|r|r|r|r|}
\hline $\mathbf{E}_{\mathbf{L}}$ & $E_{R}$ & $E_{T}$ & $G_{L R}$ & $G_{L T}$ & $\mathbf{G}_{\mathbf{R T}}$ & $v_{L R}$ & $v_{L T}$ & $v_{R T}$ \\
\hline $\mathbf{1 2 8 0 0}$ & 625 & 397 & 617 & 587 & $\mathbf{5 3}$ & 0.36 & 0.45 & 0.41 \\
\hline
\end{tabular}

Table 1: Elastic Properties of Norway Spruce, E and G in MPa [16]

Proporiétés élastiques de l'épicéa commun, E et $\mathrm{G}$ en $\mathrm{MPa}$

There is a high contrast between the longitudinal stiffness $E_{L}$ and the rolling shear stiffness $G_{R T}$. These two characteristics will thus drive the buckling of Cross Laminated Timber walls. In the present model, $R$ is chosen in out-of-plane direction and L (T respectively) is alternatively oriented in $\underline{\boldsymbol{e}}_{1}\left(\underline{\boldsymbol{e}}_{2}\right.$ respectively) and in $\underline{\boldsymbol{e}}_{2}$ directions ( $\underline{\boldsymbol{e}}_{1}$ respectively) depending on layers. In the upper and lower layers, fibers (L) are always oriented in $x_{1}$-direction.

Standard Cross Laminated Timber walls are generally made of 3 or 5 plies which have the same thickness in the present study, and comply with the mirror symmetry. In the following, the slenderness 
$\frac{b}{h}$ varies between 10 and 35 and the plate aspect $\frac{a}{b}$ varies between 0.5 and 2 to include geometries of actual structures.

\subsection{D buckling of Cross Laminated Timber walls}

\subsubsection{Buckling load and compressive strength}

The buckling load and the compressive strength of Cross Laminated Timber walls are of the same order of magnitude. Indeed, from the paper of Cabrero et al. [17], the average strength of timber in compression is $41.7 \mathrm{MPa}$. For a 5-ply Cross Laminated Timber, we may assume that only the three longitudinal plies are working in compression. Thus the compressive strength of a 5-ply Cross Laminated Timber wall may be set as $41.7 \times \frac{3}{5} \approx 25 \mathrm{MPa}$ and does not vary with $\frac{b}{h}$ and $\frac{a}{b}$ contrary to the buckling load. As an example, for a 5-ply Cross Laminated Timber square wall with a slenderness $\frac{b}{h}=25$, buckling occurs at $18.1 \mathrm{MPa}$, before wood failure (cf Fig. 5). This remark shows the necessity to take into account instabilities to design Cross Laminated Timber structures.

\subsubsection{Behavior of a Cross Laminated Timber wall across thickness}

On Figure 4, the displacement $u_{1}$ is plotted on the loaded edge for a 5-ply Cross Laminated Timber wall. Its amplitude is around one tenth of the out-of-plane deflection amplitude: in-plane displacement are not negligible.

The displacement $u_{1}$ is not linear across thickness, and thus the shear strain $\varepsilon_{13}$ is not uniform along $x_{3}$. The section of the plate doesn't remain plane during buckling because of the warping between longitudinal layers and cross layers. Indeed, longitudinal layers are stiffer than cross layers in the $x_{1}$-direction. During buckling, longitudinal layers are the most loaded plies. The upper fiber, $x_{3}=\frac{h}{2}$, is tensed whereas the lower fiber, $x_{3}=-\frac{h}{2}$, is compressed due to the bending of the plate. Since the cross layers are softer, they do not bend as longitudinal layers. The section of cross layers remains approximately vertical even during buckling. This zig-zag distribution of the in-plane displacement is well-known in laminated plates and do not comply with Hencky's kinematic assumption. On the contrary, in the Bending-Gradient theory, there are six variables (three for each direction) to capture these shear and warping effects whereas there are only two in the FOSDT which explains the better accuracy of the Bending-Gradient theory observed in the next chapter.

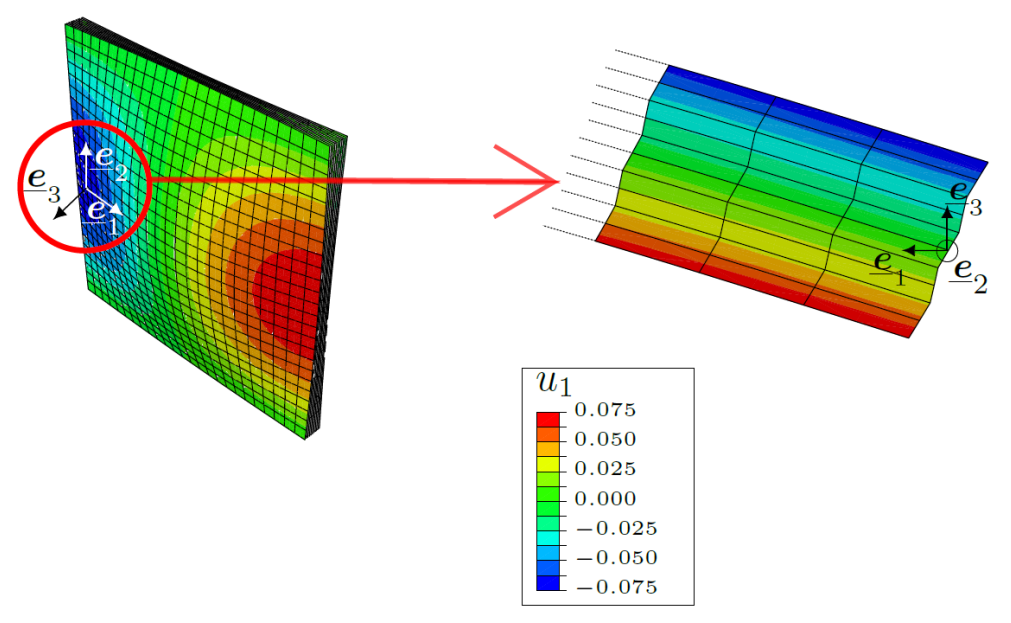

Figure 4: Displacement $u_{1}$ according to thickness on the loaded edge for a 5-ply Cross Laminated Timber square wall Déplacement $u_{1}$ selon l'épaisseur sur le bord chargé pour un mur carré en lamellé-croisé 5-plis 


\section{Comparison between numerical results and plate models}

In the following, the application of the Bending-Gradient to the linear plate buckling is compared to classical models of Kirchhoff-Love and Reissner. For the latter, the well-known FOSDT with the shear correction factor $\kappa=\frac{5}{6}$ is plotted as well as the projection of the Bending-Gradient on the Reissner model suggested in Section 2.2.3. Finally the 3D numerical calculation by finite element is used as reference to compare the accuracy of each theory.

\subsection{Results for a square plate}

Figure 5 represents the first buckling load of a 5-ply Cross Laminated Timber square wall plotted along slenderness $\frac{b}{h}$. As expected, the Kirchhoff-Love model gives results far from the actual ones: the error is even higher than $15 \%$ for a slenderness $\frac{b}{h} \leq 25$. The classical FOSDT, by considering shear effects, is more precise than the Kirchhoff-Love model. However, the error is still high. In the studied domain, the Bending-Gradient theory is clearly the model which best describes the buckling load of plates. For slenderness $\frac{b}{h}>10$, the error is less than 3.5\%, and for $\frac{b}{h}>16$ the order of magnitude of the error is less than $1.0 \%$.

It is finally noticed that the projection on a Reissner model gives almost same results as the full Bending-Gradient model: the difference is around $0.1 \%$. Using the Bending-Gradient directly seems not necessary in this case since the gain of precision compared to its projection is negligible compared to the difficulty introduced by generalizing the shear stresses.

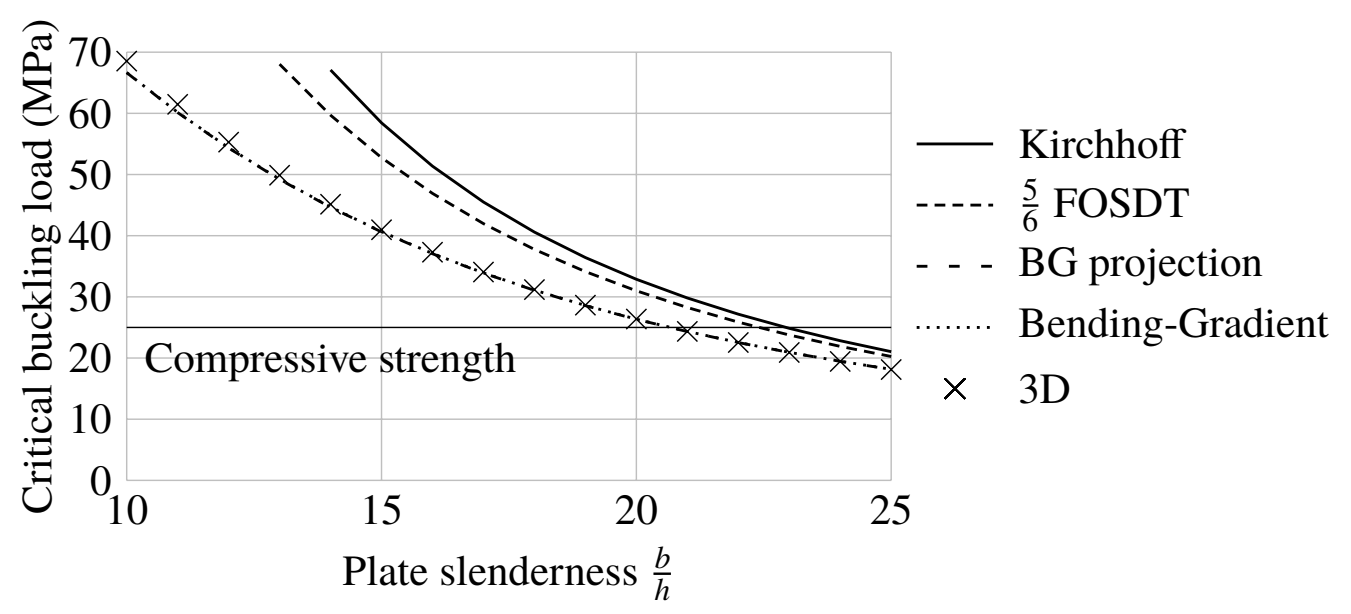

Figure 5: Buckling load according to slenderness $\frac{b}{h}$ for a 5-ply Cross Laminated Timber square wall Charge de flambement selon l'élancement $\frac{b}{h}$ pour un mur en lamellé-croisé 5-plis

Moreover the buckling load is lower than the compressive strength for slenderness $\frac{b}{h} \geq 21$ in actual structures. Thus, Cross Laminated Timber walls may buckle before the compression failure occurs which leads to the necessity to design these walls to prevent buckling. Furthermore the high sensibility to defects of the buckling compared to bending increases the risk of instabilities of actual structures.

On Figure 6, the relative error of plate models is plotted for 3-ply Cross Laminated Timber walls which are more slender: the slenderness domain here is higher than in 5-ply Cross Laminated Timber since the thickness of each ply is technologically limited to 4 centimeters. For 3-ply Cross Laminated Timber walls, the relative error of classical Kirchhoff theory and FOSDT is still high even for relatively slender structures in Cross Laminated Timber. On the contrary, the Bending-Gradient theory and its projection are close to the 3D solution in all the studied domain with a good accuracy. 


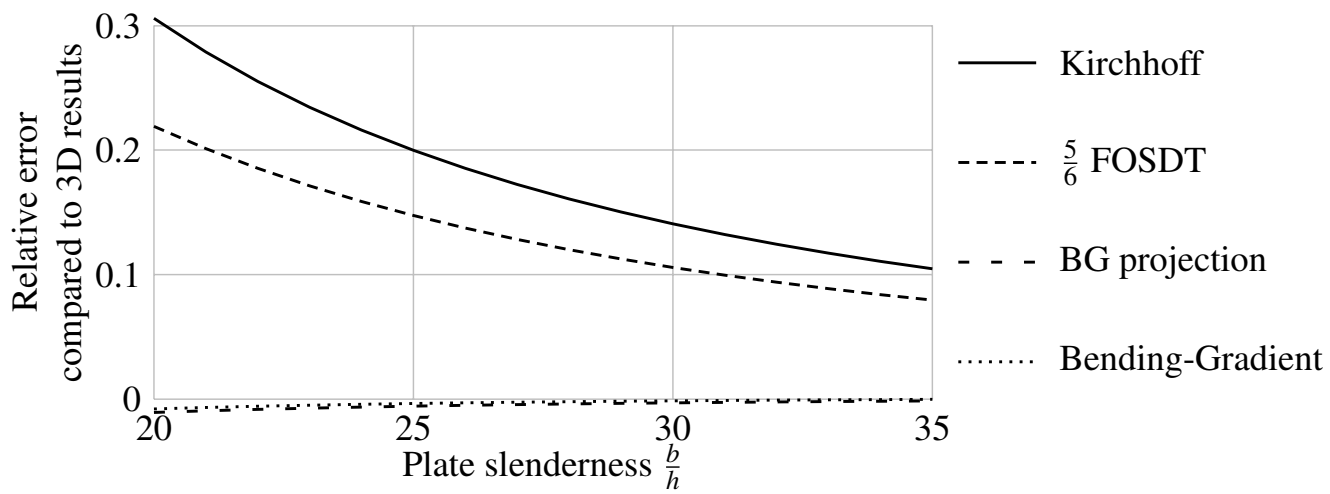

Figure 6: Relative error of plate models compared to 3D results for a 3-ply Cross Laminated Timber square wall Erreur relative des modèles de plaque comparés aux résultats 3D pour un mur en lamellé-croisé 3-plis

\subsection{Variation of the plate aspect ratio $\frac{a}{b}$}

Figure 7 represents the buckling load of a 5-ply Cross Laminated Timber with a slenderness $\frac{b}{h}=20$ for a varying plate aspect ratio. There are here successively two eigenmodes: $(m=1, n=1)$ and $(m=2, n=1)$. Quantitatively, the same results as previously are obtained: the Bending-Gradient theory and its projection are very accurate contrary to more classical models. This figure shows that the Bending-Gradient is still accurate when varying aspect ratio and even for several eigenmodes.

The Bending-Gradient's projection on the Reissner theory seems to be an appropriate model to suggest a design formula for the buckling of Cross Laminated Timber walls.

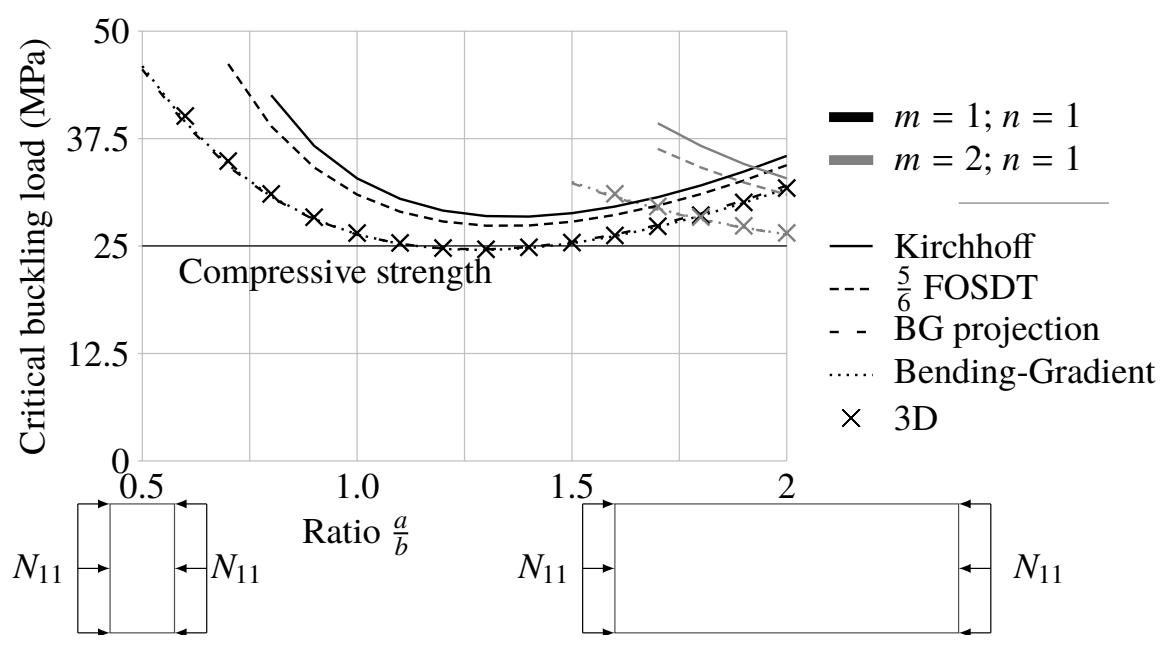

Figure 7: Buckling load according to plate aspect ratio $\frac{a}{b}$ for 5ply-Cross Laminated Timber with slenderness $\frac{b}{h}=20$ Charge de flambement selon l'aspect de plaque $\frac{a}{b}$ pour un mur en lamellé-croisé 5-plis avec un élancement $\frac{b}{h}=20$

\section{Conclusions}

In this paper, the Bending-Gradient theory has been extended to the buckling analysis which has been applied to the case of rectangular plates. A projection of this theory on a Reissner model has also been presented. A 3D numerical study has been conducted in order to get reference results for the buckling of Cross Laminated Timber walls. Results have shown that, qualitatively and quantitatively, the Bending-Gradient is well adapted for the study of the buckling of thick and highly anisotropic laminated plates such as Cross Laminated Timber contrary to the FOSDT and the Kirchhoff model. Moreover, the suggested projection of the Bending-Gradient, proved to be also very accurate, seems thus more adapted than the full Bending-Gradient theory to engineering issues since it uses a simpler 
model, the Reissner model, without loosing accuracy. Indeed, this projection could be used to suggest a new engineering design recommendation for the resistance of Cross Laminated Timber walls. To this end, imperfections of actual structures and variability of the timber characteristics, in particular the rolling shear stiffness have to be investigated in a further work. To be complete, creep should also be studied to evaluate the influence of permanent loading across time.

\section{References}

[1] GR Kirchhoff. Uber das gleichgewicht und die bewegung einer elastischen scheibe. 1850.

[2] Arthur W Leissa. Buckling of laminated composite plates and shell panels. Technical report, DTIC Document, 1985.

[3] H Hencky. Über die berücksichtigung der schubverzerrung in ebenen platten. Ingenieur-Archiv, 16(1):72-76, 1947.

[4] E Reissner. The effect of transverse shear deformation on the bending of elastic plates. Journal of Applied Mechanics, 12:69-77, 1945.

[5] TS Chow. On the propagation of flexural waves in an orthotropic laminated plate and its response to an impulsive load. Journal of Composite Materials, 5(3):306-319, 1971.

[6] JM Whitney. Stress analysis of thick laminated composite and sandwich plates. Journal of Composite Materials, 6(4):426-440, 1972.

[7] Z Kaczkowski. Plates. statical calculations, 1968.

[8] SA Ambartsumian. Analysis of two-layer orthotropic shells. Investiia Akad Nauk SSSR, Ot Tekh Nauk, 7:93-106, 1957.

[9] SA Ambartsumian. Two analysis method for two-layer orthotropic shells. Izv. An. Arm. SSR Seiya Fiz-Matem nauk, 10(2), 1957.

[10] A Lebée and K Sab. A bending-gradient model for thick plates. part i: Theory. International Journal of Solids and Structures, 48(20):2878-2888, 2011.

[11] A Lebée and K Sab. A bending-gradient model for thick plates, part ii: Closed-form solutions for cylindrical bending of laminates. International Journal of Solids and Structures, 48(20):28892901, 2011.

[12] O. Perret, A. Lebée, C. Douthe, and K. Sab. The bending-gradient theory for the linear buckling of thick plates: Application to cross laminated timber panels. International Journal of Solids and Structures, 2016.

[13] A Lebée and K Sab. Homogenization of Heterogeneous Thin and Thick Plates. John Wiley and Sons, 2015.

[14] A Lebée and K Sab. On the generalization of reissner plate theory to laminated plates, Part I: Theory. Journal of Elasticity, 1-28, 2016.

[15] A Lebée and K Sab. On the generalization of reissner plate theory to laminated plates, Part II: Comparison with the bending-gradient theory. Journal of Elasticity, 1-28, 2016.

[16] Daniel Keunecke, Stefan Hering, and Peter Niemz. Three-dimensional elastic behaviour of common yew and norway spruce. Wood science and technology, 42(8):633-647, 2008.

[17] JM Cabrero, C Blanco, KG Gebremedhin, and A Martin-Meizoso. Assessment of phenomenological failure criteria for wood. European Journal of Wood and Wood Products, 70(6):871-882, 2012. 